\title{
Cost-effectiveness of sunitinib as second-line treatment for gastrointestinal stromal tumor in the People's Republic of China [Corrigendum]
}

\author{
Li J, Ren HY, Zhang J, et al. Comparative Effectiveness \\ Research. 2017;7:1-9
}

On page 8, Acknowledgments section, "The abstract of this study was presented at the ISPOR $18^{\text {th }}$ Annual European Congress as a poster presentation with interim findings. The poster's abstract was published in "Poster Abstracts" in Value In Health 2015 November issue. ${ }^{21}$ " should have been "The abstract of this study was presented at the ISPOR $18^{\text {th }}$ Annual European Congress as a poster presentation with interim findings. The poster's abstract was published in "Poster Abstracts" in Value In Health 2015 November issue. ${ }^{21}$ The authors thank Dr. Liheng Ma from China Pfizer Medical, who provided medical insight in the study design phase and helped to secure the research funding. This work would not have been possible without such support." 